\title{
Use of Quadruple Zygoma Implants Technique for Atrophic Maxilla Rehabilitation with Immediate Loading - A Clinical Case Report
}

\author{
García Lozada V* \\ DDS Central University of Venezuela, MSc University of Lleida, Spain \\ Department of Oral and Maxillofacial Implantology, Cibumax, Spain
}

*Corresponding author: García Lozada V, DDS, Central University of Venezuela, MSc University of Lleida, Department of Oral and Maxillofacial Implantology, Cibumax, Spain, E-mail: vleogl@hotmail.com

Citation: García Lozada V (2018) Use of Quadruple Zygoma Implants Technique for Atrophic Maxilla Rehabilitation with Immediate Loading - A Clinical Case Report. J Oral Health Dent 2: 206

Article history: Received: 24 January 2018, Accepted: 13 June 2018, Published: 15 June 2018

\begin{abstract}
The maxilla with great atrophy can be due to various factors such as tumor resection, generalized aggressive periodontitis, genetic disorders or syndromes. The rehabilitation of patients with an atrophic edentulous maxilla presents a significant challenge for surgeons, and the treatment concept with zygomatic implants have evolved as an alternative for bone augmentation procedures. The aim of this review is to describe the rehabilitation of the maxillary with the use of four zygomatic implants (quad-zygoma implant technique). Within the limitations of this observation, we can state that full mouth rehabilitation with quadruple zygomatic implants technique can definitely be considered as a viable treatment option treating patients with atrophic maxilla. However, studies with more follow-up time and controlled clinical trials should be done in order to document the longevity of this kind of treatment modality.
\end{abstract}

Keywords: Atrophic Maxilla; Quad Zygomatic Implants; Immediate Loading

\section{Introduction}

Atrophic maxilla can be due to various factors from bone loss, tumor resection or other genetic disorders and syndromes [1]. Fabrication of prosthesis with adequate retention and stability for patients with an atrophic edentulous maxilla presents a significant challenge. The aim of rehabilitation is not only to provide a cosmetically acceptable appearance, but also to restore oral functions, such as deglutition, mastication, and phonation [2]. Treatment options for edentulous patients include tissue-supported removable prosthesis, implant-supported removable prosthesis, and implant-supported fixed prosthesis. Implant-supported fixed prostheses have been proved to have high success rates in restoring facial esthetics, speech and function in these individuals [2,3]. The presence of inadequate bone quantity produce a potential problem for implant placement needing bone augmentation procedures. For decades, the atrophy of the maxillary process has been treated by large grafts from the iliac crest or calota in the form of onlays, in combination or not with a segmental osteotomy type Lefort; or by sinus inlays. Clinical studies with a long follow-up time reveal disparity in the survival of the implants after these procedures; Success depends to a large extent on the amount of preexisting bone in the residual bone crest and on the appearance of complications derived from the grafted area [4-10]. However, bone grafting procedures have few limitations like need for hospitalization, morbidity of donor site, unpredictable resorption of the bone graft, and delayed placement of the implant for the graft consolidation time [11-13].

Treatment concepts with zygomatic implants have evolved as an alternative for bone augmentation procedures. Combination of conventional implants and zygomatic implants has been used successfully for restoration of atrophic maxilla [5,14-20]. The placement of anterior conventional implants without grafting will be extremely difficult in severely atrophic premaxilla. In such situations, quadruple zygomatic implants can be used for the restoration of the edentulous maxilla [21-23]. This clinical case describes the restoration of the maxillary dentition using four zygomatic implants (quad zygomatic implant technique).

\section{Clinical case}

Female patient, 74 years old without major systemic disease, only slight hypertension but properly controlled. Presented an edentulous maxilla with resorption and with a complete prosthesis badly adapted with high mobility, reporting problems with poor chewing function and searching a treatment without the need of bone graft and the possibility to have a fixed restoration. 
The same went to the Center of Dental Specialties to the service of Oral and Maxillofacial Implantology (Cibumax) for examination, diagnosis and resolution of problems.

After the clinical, radiographic examination and definition of the treatment plan to be performed, a conscious sedation in hospital was improved with midazolam, was infiltrated $4 \%$ articaine and bupivacaine anesthetic for nerve block (Figure 1 and 2).

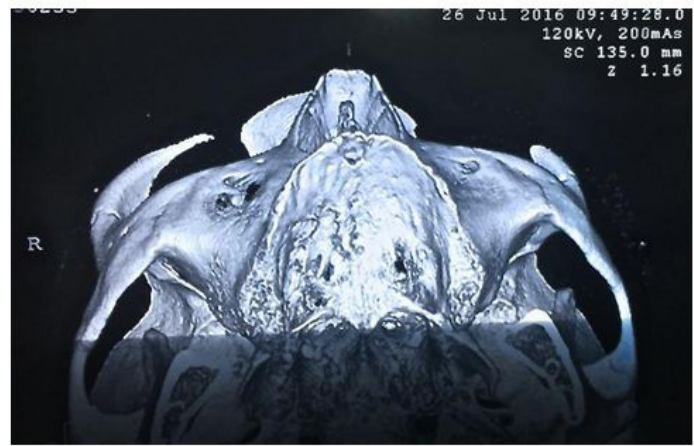

Figure 1: Pre-operative 3D axial

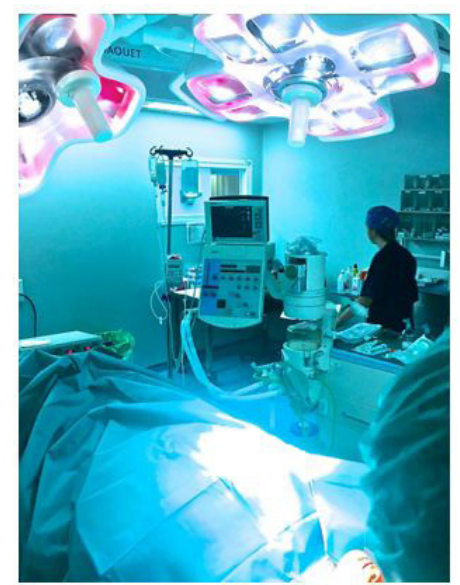

Figure 2: Hospital at Cibumax service in Spain

After the clinical, radiographic examination and definition of the treatment plan to be performed, a conscious sedation in hospital was improved with midazolam, was infiltrated $4 \%$ articaine and bupivacaine anesthetic for nerve block (Figure 1 and 2).
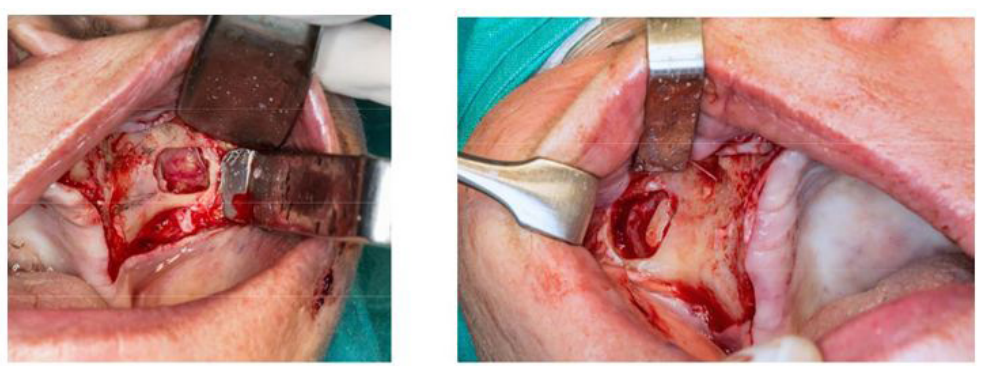

Figure 3: Clinical picture of mucoperiosteal flap and lateral sinus window

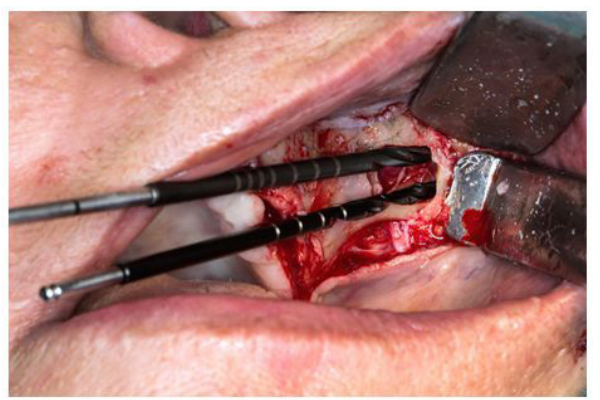

Figure 4: Clinical picture of drills osteotomies in left malar 
The anterior zygomatic implants Neodent ${ }^{\circledast} 4 \times 52.5 \mathrm{~mm}$ were placed engaging the zygomatic bone with their platforms emerging at the canine region $\# 13,23$. The posterior zygomatic implants Neodent ${ }^{\circledR} 4 \times 45 \mathrm{~mm}$ were placed through the infra-zygomatic crest emerging near the second premolar region \#15,25; all zygomatic implants with a torque insertion of $65 \mathrm{Nw}$ (Figure 5 and 6 ). We placed 2 pterygoid implants Neodent ${ }^{\circledast} 4 \mathrm{x} 17 \mathrm{~mm}$ in \#17, 27 position, with $30 \mathrm{Nw}$ of torque insertion for better support in the final restoration, we prefer not attached these pterygoids implants with the immediate loading for the low torque of them.

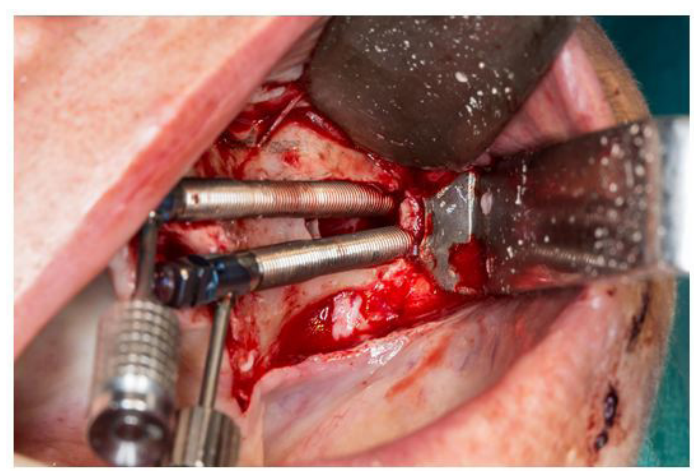

Figure 5: Zygomatic implants placed in the left malar

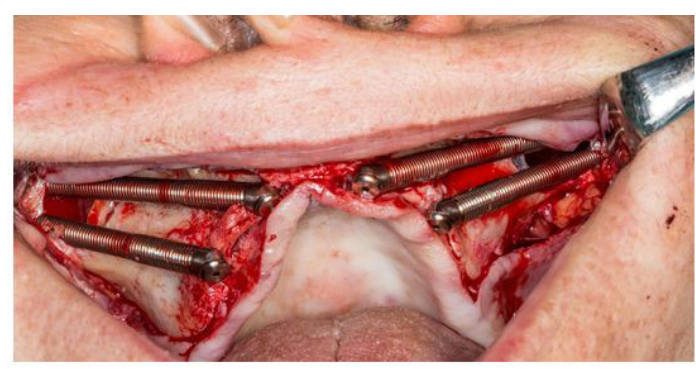

Figure 6: Placement of 4 zygomatic implants in the maxilla

Straight multiunit abutments neodent ${ }^{\circledR}$ were placed for the preparation of a provisional complete fixed immediate load prosthesis, continuing with the closure flap sutures with black silk 000 (Figure 7).

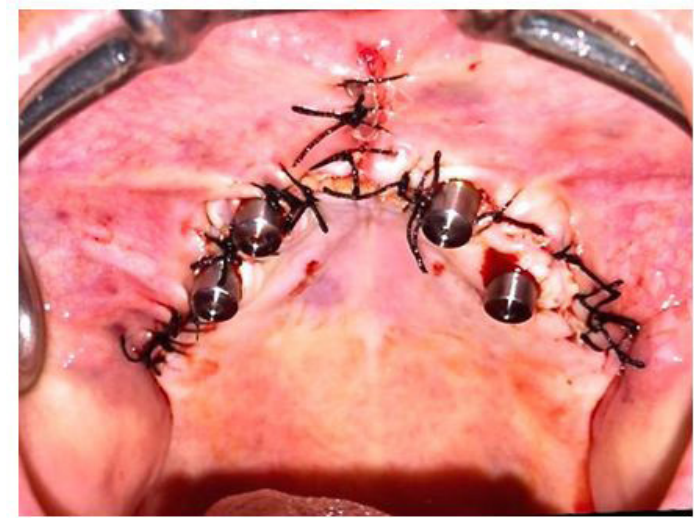

Figure 7: Clinical picture of multiunit abutments placed and sutures

Impressions, bite registration tests and tooth color were taken for the preparation of the provisional immediate load prosthesis to be installed the same day of the implant surgery, and to do its respective postoperative radiographic record (Figure 8 and 9).

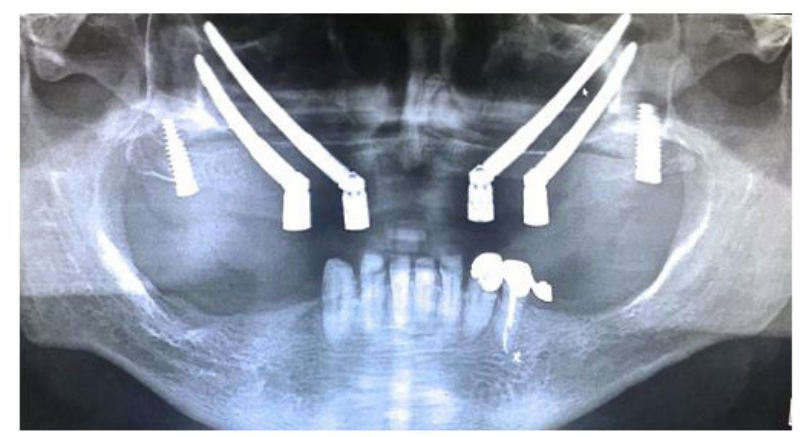

Figure 8: Post-operative radiograph 


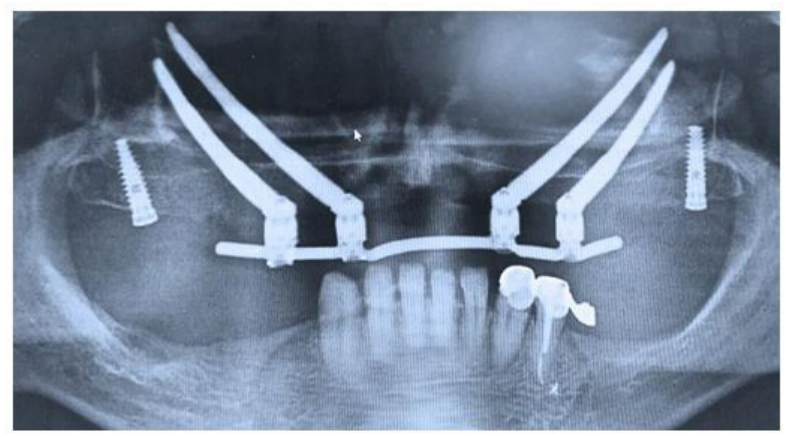

Figure 9: Post-operative radiograph with immediate loading prosthesis fixed

The surgical procedure was performed without complications, achieving a good primary stability of the implants to be able to perform the provisional immediate load prosthesis and thus the patient reincorporate to their social life as soon as possible getting a comfort and aesthetics quite pleasant.

\section{Discussion}

Zygomatic implants in the atrophic maxilla have been reported to be clinically successful [8-15]. Considering the high success rate of zygomatic implants and the need for immediate fixed prosthesis without grafting procedures, the use of four zygomatic implants for a maxillary fixed prosthesis can be a valuable treatment option [22-24].

The placement of double zygomatic implants bilaterally is well documented in the literature, with an extremely low implant loss rate [10,24-27].

This clinical report suggests that the placement of 4 zygomatic implants with immediate occlusal loading is a viable and effective treatment option for the rehabilitation of severely resorbed maxillae alternatively to maxillary reconstruction with autogenous bone grafts.

The anatomical configuration of the maxilla and zygomatic bone facilitated an extra sinus approach for placement of the zygomatic implants with a good primary stability, more than $60 \mathrm{Nw}$ of torque allowing the application of an immediate loading prosthesis.

\section{Conclusion}

The literature and our experience, shows that the technique with four zygomatic implants give good clinical results for the rehabilitation of atrophic jaws, with the added possibility of immediate loading of them and thus return the chewing and aesthetic function in a faster way to the use of bone grafts. This procedure requires through knowledge of the technique, superior surgical skills and meticulous training in prosthetic rehabilitation. We can state that full mouth rehabilitation with quadruple zygomatic implant technique can definitely be considered as a viable treatment option treating patients with atrophic maxilla. However, studies with more follow-up time and controlled clinical trials should be done in order to document the longevity of this treatment modality.

\section{References}

1.Uchida Y, Goto M, Katsuki T, Akiyoshi T (2001) Measurement of the maxilla and zygoma as an aid in installing zygomatic implants. J Oral Maxillofac Surg 59: $1193-8$.

2. Allison PJ, Locker D, Feine JS (1997) Quality of life: A dynamic construct. Soc Sci Med 45: 221-30.

3. Jemt T, Johansson J (2006) Implant treatment in the edentulous maxillae: A 15-year follow-up study on 76 consecutive patients provided with fixed prostheses. Clin Implant Dent Relat Res 8: 61-9.

4. Aparicio Magallon C, Soto yarritu R (2008) Que indicaciones tienen y que resultados nos ofrece los implantes cigomáticos. Cient Dent 1: 69-80.

5. Garcia Lozada V (2015) Utilization of zygomatic implants for the rehabilitation of the atrophic maxilla: About a case [Utilización de implantes cigomáticos para la rehabilitación del maxilar atrófico: A proposito de un caso]. Revista Maxillaris 188: 92-103.

6. Becktor JP, Hallstroem H, Isaksson S, Sennerby L (2008) The use of particulate bone grafts from the mandible for maxillary sinus floor augmentation before placement of sur- face-modified implants: results from bone grafting to delivery of the final fixed prosthesis. J Oral Maxillofac Surg 66: 780-6.

7. Collins TA, Brown GK, Johnson N, Massey JA, Nunn BD (1995) Team management of atrophic edentulous with autogenous inlay, veneer, and split grafts and endosseous implants: case reports. Quintessence Int 26: 79-93.

8. Graziani F, Dono N, Needleman N, Gabriele M, Tonetti M (2004) Comparison of implant survival following sinus floor augmentation procedures with implants placed in the pristine posterior maxillary bone: a systematic review. Clin Oral Implants Res 15: 677-82.

9. Hallman M, Hedin M, Sennerby L, Lundgren S (2002) A prospective 1-year clinical and radiographic study of implants placed after maxillary sinus floor augmentation with bovine hydroxyapatite and autogenous bone. J Oral Maxillofac Surg 60: 277-84.

10. Davó R, Felice P, Pistilli R, Barause C, Martí-Pages C, et al. (2018) Immediately loaded zygomatic implants vs conventional dental implants in augmented atrophic maxillae: 1 year post-loading results from a multicentre randomised contolled trial. Eur J Oral Implantol 11: 145-61. 
11. Seiler JG 3rd, Johnson J (2000) Iliac crest autogenous bone grafting: Donor site complications. J South Orthop Assoc 9: 91-7.

12. Arrington ED, Smith WJ, Chambers HG, Bucknell AL, Davino NA (1996) Complications of iliac crest bone graft harvesting. Clin Orthop Relat Res 329: $300-9$.

13. Rasmusson L, Meredith N, Cho IH, Sennerby L (1999) The influence of simultaneous versus delayed placement on the stability of titanium implants in onlay bone grafts. A histologic and biomechanic study in the rabbit. Int J Oral Maxillofac Surg 28: 224-31.

14. Malevez C, Abarca M, Durdu F, Daelemans P (2004) Clinical outcome of 103 consecutive zygomatic implants: A 6-48 months follow-up study. Clin Oral Implants Res 15: 18-22.

15. Bedrossian E (2010) Rehabilitation of the edentulous maxilla with the zygoma concept: A 7-year prospective study. Int J Oral Maxillofac Implants 25: 1213-21. 16. Yates JM, Brook IM, Patel RR, Wragg PF, Atkins SA, et al. (2014) Treatment of the edentulous atrophic maxilla using zygomatic implants: Evaluation of survival rates over 5-10 years. Int J Oral Maxillofac Surg 43: 237-42.

17. Maló P, de Araújo Nobre M, Lopes A, Ferro A, Moss S (2015) Extramaxillary surgical technique: Clinical outcome of 352 patients rehabilitated with 747 zygomatic implants with a follow-up between 6 months and 7 years. Clin Implant Dent Relat Res Suppl 1: 153-62.

18. Aparicio C, Manresa C, Francisco K, Ouazzani W, Claros P, et al. (2014) The long-term use of zygomatic implants: A 10-year clinical and radiographic report. Clin Implant Dent Relat Res 16: 447-59.

19. Migliorança RM, Sotto-Maior BS, Senna PM, Francischone CE, Del Bel Cury AA (2012) Immediate occlusal loading of extrasinus zygomatic implants: A prospective cohort study with a follow-up period of 8 years. Int J Oral Maxillofac Surg 41: 1072-6.

20. García Lozada V (2015) Zygomatic implants and All-on-4 technique with immediate loading for prosthetic rehabilitation complete bimaxilla in severe atrophies: A case report [Implantes cigomáticos y técnica All-on-4 con carga inmediata para rehabilitación protésica completa bimaxilar en atrófias severas: A propósito de un caso]. Gaceta Dental 265: 142-8.

21. Davo R, Pons O, Rojas J, Carpio E (2010) Immediate function of four zygomatic implants: A 1-year report of a prospective study. Eur J Oral Implantol 3: 323-34. 22. Davó R, Pons O (2013) Prostheses supported by four immediately loaded zygomatic implants: A 3-year prospective study. Eur J Oral Implantol 6: 263-9.

23. Padovan LE, Ribeiro-Júnior PD, Sartori IA, Thomé G, Sartori EM, et al. (2015) Multiple zygomatic implants as an alternative for rehabilitation of extremely atrophic maxilla: A case letter with 55 months of follow-up. J Oral Implantol 41: 97-100.

24. Duarte LR, Filho HN, Franciscone CE, et al. (2007) The establishment of a protocol for the total rehabilitation of atrophic maxillae employing four zygomatic fixtures in an immediate loading systemVa 30-month clinical and radiographic follow-up. Clin Implant Dent Relat Res 9: 186-96.

25. Balshi TJ, Wolfinger GJ, Petropoulos VC (2003) Quadruple zygomatic implant support for retreatment of resorbed iliac crest bone graft transplant. Implant Dent 12: 47-53.

26. Bothur S, Jonsson G, Sandahl L (2003) Modified technique using multiple zygomatic implants in reconstruction of the atrophic maxilla: a technical note. Int J Oral Maxillofac Implants 18: 902-4

27. Davo R, Malevez C, Rojas J (2007) Immediate function in the atrophic maxilla using zygoma implants: a preliminary study. J Prosthet Dent 97: 44-51. 